\title{
Correction to: Surface Rupture Effects on Earthquake Moment-Area Scaling Relations
}

\author{
Yingdi Luo, ${ }^{1}$ Jean-Paul Ampuero, ${ }^{1}{ }^{\text {Ken Miyakoshi, }}{ }^{2}$ and Kojiro Irikura ${ }^{3}$
}

\author{
Correction to: Pure Appl. Geophys. (2017) \\ 174:3331-3342 \\ https://doi.org/10.1007/s00024-017-1467-4
}

The Eq. (10) in the article was displayed incorrectly. The correct version of Eq. (10) should be as follows:

$$
C\left(\frac{L}{W_{\mathrm{s}}}\right)=\frac{\pi}{8}\left(7-\frac{7-16 / \pi^{2}}{1+\left(2 W_{\mathrm{s}} / L\right)^{2}}\right) .
$$

We would like to acknowledge Prof. Ralph Archuleta, Research Professor and Professor Emeritus from Dept. of Earth Science of University of California, Santa Barbara for discovering this mistake.

2 Geo-Research Institute (GRI), Osaka, Japan.

3 Aichi Institute of Technology (AIT), Toyota, Japan. 